\title{
Tempos históricos plurais: Braudel, Koselleck e o problema da escravidāo negra nas Américas
}

\author{
Plural historical times: Braudel, Koselleck and the problem of \\ African slavery in the Americas
}

\section{Rafael de Bivar Marquese \& Waldomiro Lourenço da Silva Júnior}

\section{RESUMO}

Neste artigo exploram-se as interconexões entre as formulações de Fernand Braudel e Reinhart Koselleck a respeito do tempo histórico. Na primeira parte, após passarmos em revista os aspectos centrais do modelo braudeliano, procuramos demonstrar a forma como Koselleck se apropriou dele, renovando e radicalizando-o mediante um duplo procedimento de condensação e complexificação. Na segunda parte, por meio de um breve balanço historiográfico, exploramos as potencialidades da teorização braudel-koselleckiana no campo específico da escravidão negra nas Américas, expondo uma agenda de pesquisa renovada.

\section{PALAVRAS-CHAVE}

Fernand Braudel; Historiografia sobre escravidão; Reinhart Koselleck

\section{ABSTRACT}

The article analyses the formulations on historical time made by Fernand Braudel and Reinhart Koselleck and their interconnections. In the first part, after reviewing the central aspects of the Braudelian model it demonstrates how Koselleck appropriated it, renewing and radicalizing it by a double procedure of condensation and complexification. In the second part, through a brief historiographic survey it explores the potentialities of Braudelian / Kosellekian theorization for the study of New World Slavery, presenting a renewed research agenda.

\section{KEYWORDS}

Fernand Braudel; Historiography of Slavery; Reinhart Koselleck 


\section{A experiência da guerra}

Além de ameaçar o mundo com as trevas da barbárie nazista, a $2^{\text {a }}$ Guerra Mundial poderia ter liquidado precocemente duas das mais poderosas mentes teóricas da historiografia do século XX. O lado francês dessa história é relativamente bem conhecido entre nós brasileiros. Pouco menos de dois anos após regressar de sua experiência docente na Universidade de São Paulo, Fernand Braudel viu eclodir o novo conflito internacional. Imediatamente reconvocado pelo exército francês para o posto de tenente de artilharia, foi alocado no sistema defensivo da Linha Maginot. Em 29 de junho de 1940, uma semana após a assinatura do armistício, caiu prisioneiro das forças alemãs junto a centenas de outros oficiais franceses. $O$ ofício de historiador seria a válvula de escape para que suportasse a ruína de seu país e os cinco anos de cativeiro nas cidades alemãs de Mogúncia (1940-42) e Lübeck (1942-45). O cárcere do oficialato era menos rigoroso que outros campos de concentração. Por isso, Braudel pôde proferir palestras para os outros prisioneiros, corresponder-se periodicamente com Lucien Febvre e trabalhar na escritura de sua tese sobre o Mediterrâneo. Para tanto, além de sua prodigiosa memória e de algumas fichas de pesquisa que conseguiu obter por correio, foi importante a consulta de livros e periódicos disponíveis em bibliotecas locais, vindo a incorporar um considerável repertório historiográfico de procedência germânica (DAIX 1999, p. 199-206).

No final de 1941, Braudel concluiu uma primeira versão da tese, redesenhado o esboço preliminar feito em 1939. Em Lübeck, em meio às reviravoltas da guerra, escreveria outras três versões do trabalho, refinando gradualmente o seu modelo de análise e a formulação teórica que viria a lume mais tarde. No entanto, a reação de Hitler aos bombardeios de Dresden, entre 13 e 15 de fevereiro de 1945, quase pôs tudo a perder. Como vingança pelo incêndio dantesco da "Florença do Elba", o líder nazista pensou seriamente em dar prosseguimento à proposta 
de Goebbels para que os SS preparassem o assassinato com lança-chamas de todos os oficiais estrangeiros sob sua guarda. A ação foi abortada, em abril, com as tratativas secretas de Himmler para assinar um armistício com os Aliados. Somente 15 anos depois Braudel viria saber, horrorizado, dos riscos que sua vida correra ao final da guerra. Seu campo de concentração em Lübeck foi libertado pelas tropas britânicas em 2 de maio de 1945 (DAIX 1999, p. 236).

Exatamente um dia antes, em Bohumin (na fronteira da atual República Checa com a Polônia), Reinhart Koselleck caiu prisioneiro do Exército Vermelho. 21 anos mais novo que Braudel, o futuro historiador alemão viveu a $2^{\text {a }}$ Guerra Mundial em liberdade, mas, ao cabo dela, o horror também Ihe tocou. Sua adolescência e juventude foram moldadas pelo regime nazista. Em 1934, aos 11 anos de idade, entrou para a Juventude Hitlerista. Em 1941, no final do Gymnasium, Koselleck se voluntariou, com todos seus colegas de classe, ao serviço militar, partindo já no final daquele ano para o front russo. No verão de 1942, estava alocado como soldado das divisões de artilharia do exército alemão. Em marcha para Stalingrado, o acaso veio Ihe salvar: logo no início da campanha que mudaria a trajetória da guerra, um caminhão atropelou o pé de Koselleck, e ele acabou sendo deslocado para funções bem mais leves nas divisões de radares antiaéreos estacionadas na França. A rápida dilapidação da Wehrmacht no ano final da guerra o trouxe de volta aos campos de batalha no Front Leste, agora como soldado de infantaria. Em primeiro de maio de 1945, na véspera da libertação de Braudel em Lübeck, a divisão de Koselleck se rendeu aos soviéticos, que imediatamente a obrigaram a marchar até Auschwitz. Nas semanas seguintes, sob regime de trabalho forçado, Koselleck tomou ciência do que lá ocorrera. À experiência direta no mais infame campo de extermínio da história, onde quase teve a cabeça esmagada por um antigo prisioneiro polonês, Koselleck seguiu para um campo de trabalho compulsório no Cazaquistão soviético, de onde foi liberado, um ano e meio depois, por invalidez - novamente, seu pé estropiado o salvando (OLSEN 2012, p. 11-13). 
Vemos, nesses episódios que acabamos de narrar, o peso de forças históricas de natureza estrutural na delimitação das opções dadas às trajetórias individuais de dois historiadores que se destacariam, nas décadas seguintes, justamente por teorizar de forma bastante original a natureza daquelas forças. Mas, vemos também o peso do acaso nelas, isto é, de ocorrências circunstanciais (Braudel estacionado na Linha Maginot, e não nos Alpes; o atropelamento de Koselleck) que, em certo grau, determinaram o que efetivamente ocorreu com cada um deles. A experiência de ambos com as atrocidades da $2^{\text {a }}$ Guerra Mundial foi decisiva para o que viriam a fazer depois dela. Ainda que o projeto de enfrentar a problemática da duração histórica já estivesse no horizonte de Braudel antes de 1939, o tempo do cativeiro sob os nazistas teve papel de relevo para a formulação definitiva do modelo tripartite dos tempos históricos que tanto o notabilizaria. Por outro lado, toda a produção historiográfica de Koselleck - da crítica à potência autoritária e desestabilizadora do iluminismo à conceituação dos estratos do tempo - constituiu um constante esforço para dar conta do que foi a "experiência primária", corporal, da guerra.

Eis como iremos organizar o artigo, que irá operar em dois planos distintos, porém articulados. Na primeira parte, apresentaremos o arco de diálogos historiográficos sobre o problema da teorização do tempo histórico que vai de Braudel a Koselleck, centrando-nos em especial na natureza da apropriação que o segundo historiador fez do trabalho do primeiro. Sem negar outras influências importantes para as formulações de Koselleck sobre o tempo histórico, o objetivo, aqui, é entender como historiador alemão contribuiu para solucionar o problema da "indigência teórica da ciência da história", por meio do duplo procedimento de condensação e complexificação da proposta braudeliana sobre a pluralidade dos tempos históricos. Na segunda parte do artigo, efetuaremos um breve exame historiográfico e teórico da escravidão negra nas Américas, procurando discutir as implicações e as potencialidades da teorização braudel-koselleckiana para o campo específico de investigação no qual atuamos. 
A escravidão é um fenômeno que, tanto pela sua amplidão milenar na história humana quanto por suas muitas peculiaridades verificadas nos diferentes locais onde existiu, oferece possibilidades privilegiadas para a exploração do quadro teórico que será apresentado com maior vagar na primeira parte do artigo. Mesmo que os historiadores de diferentes tendências e gerações tenham concebido e estudado a ocorrência de variações e transformações significativas, a forma como experiências e movimentos históricos de múltiplas durações se combinaram no tempo e no espaço, dando origem a fases sincrônicas e diacrônicas do sistema de escravidão, ainda está em grande medida por ser explorada. A consideração dos estratos de tempo que compuseram o cativeiro das populações de origem africana no Novo Mundo pode nos conduzir a uma agenda de pesquisa renovada.

\section{De Braudel a Koselleck}

Em maio de 1946, Braudel deu por finalizado seu Doctorat d'État, escrito em sua maior parte nas condições que acabamos de sumariar. A teorização que então apresentou para apreender os distintos tempos históricos do Mediterrâneo na segunda metade do século XVI se fundava nos diálogos interdisciplinares anteriores dos historiadores associados à revista dos Annales. Com efeito, para dar conta de "uma história quase imóvel, a do homem em suas relações com o meio que o cerca", Braudel apresentava o conceito de um "tempo geográfico"; "acima dessa história imóvel", prosseguia ele, haveria "uma história lentamente ritmada, dir-se-ia de bom grado, não fosse a expressão desviada de seu sentido pleno, uma história social, a dos grupos e dos agrupamentos", que compreendia o "tempo social"; por fim, a história dos acontecimentos contra a qual se voltara o sociólogo François Simiand no começo do século XX, apreendida a partir da chave do "tempo individual" (BRAUDEL 2016, p. 63-64). Constituindo-se em três planos temporais geográfico, social e individual - distintos e sobrepostos, que significavam, em termos de elaboração teórica, um avanço 
ainda relativamente modesto em relação às grandes obras redigidas antes da guerra por Lucien Febvre e Marc Bloch.

O salto teórico definitivo de Braudel demandou o aparecimento de um novo e poderosíssimo adversário no campo francês das ciências humanas, a antropologia estrutural de Claude LéviStrauss, outro ex-professor da Universidade de São Paulo, que igualmente passou por uma experiência crucial de deslocamento durante a $2^{\text {a }}$ Guerra Mundial - no caso, o exílio em Nova Iorque, quando se tornou professor da New School e estabeleceu estreito contato com o linguista russo Roman Jakobson. Às Estruturas Elementares do Parentesco, tese de doutorado escrita durante a Segunda Guerra Mundial e editada ainda nos Estados Unidos, em 1947, seguiu-se, dois anos depois, a composição do artigomanifesto "História e Etnologia" - posteriormente transformado no ensaio de abertura do volume Antropologia Estrutural, publicado no início de 1958 (LÉVI-STRAUSS 1995, p. 49-72; DOSSE 1993, p. 31-52).

A história e a etnologia, argumentava Lévi-Strauss, partilhavam um chão comum ao estudarem a vida social humana, diferenciando-se, no entanto, pelo fato de a segunda tratar fundamentalmente do que escapava à consciência imediata dos seres humanos, isto é, as "condições inconscientes da vida social". A antropologia, assim, tinha por meta descortinar os elementos invariantes capazes de explicar as forças universais presentes em todas as práticas sociais. Na avaliação de LéviStrauss, o saber histórico, embora necessário, mostrara-se insuficiente para dar conta de tal desafio em razão de seu caráter eminentemente ideográfico. Ao atribuir a Marx o aforismo de que "os homens fazem sua própria história, mas não sabem que a fazem", fincando a etnologia no segundo termo, LéviStrauss acreditava ter lançado as bases da cientificidade de um saber eminentemente nomotético (LÉVI-STRAUSS 1995, p. 70; REIS 2012, p. 177-178; DOSSE 1992, p. 109-110).

As reações à posição anti-história de Lévi-Strauss vieram, de início, do campo da filosofia. Claude Lefort, ainda aliado politicamente a Jean-Paul Sartre, salientou em artigo de 
1952 como a perspectiva etnológica de Lévi-Strauss anulava o tempo histórico. A saída que Lefort ofereceu, recorrendo à categoria heideggeriana da historicidade, consistiu em apontar como as chamadas "sociedades frias" organizavam seu tempo de forma distinta das sociedades ditas "históricas" (LEFORT 1979, p. 37-56). ${ }^{1}$ Sartre, por sua vez, enfrentou o problema da possibilidade de constituir uma antropologia simultaneamente "estrutural e histórica" cinco anos depois, nas páginas de Les Temps Modernes, em "Questão de Método", posteriormente convertida em abertura à Crítica da Razão Dialética (SARTRE 1978, p. 111-191).

Foi somente neste momento, em 1958, que se deu a entrada de Braudel no debate. O historiador respondeu ao desafio da antropologia com a categoria da duração, ausente tanto na resposta de Lefort como na de Sartre. Ao fazê-lo, apresentou o que pode ser tomado como a principal formulação teórica de todo o movimento dos Annales: a decomposição do tempo histórico entre longa duração, conjuntura e evento. Na medida em que História e Ciências Sociais: A Longa Duração é um texto matricial para a nossa profissão, sobejamente conhecido, queremos destacar tão somente três pontos de seu argumento.

O primeiro diz respeito à crítica algo frequente de que o artigo programático de 1958 pouca teorização teria trazido para além de uma defesa difusa do primado da longa duração como uma ferramenta analítica capaz de unificar os esforços de investigação da história aos da sociologia, da antropologia e da economia. É de uma assertiva como essa que deriva, por exemplo, a avaliação de François Dosse sobre o "efeito Braudel" para as gerações posteriores dos Annales, vale dizer, uma suposta ausência de um eixo teórico mínimo, impactando negativamente os historiadores que vieram depois dele. A carência de teorização se expressaria notadamente no tratamento do conceito de estrutura, tomado de empréstimo de Lévi-Strauss para descrever o que antes Braudel denominara como o "tempo geográfico". A concepção braudeliana de estrutura, afirma Dosse (1992, p. 115-116),
1 - A crítica de Lefort foi incorporada por Lévi-Strauss em artigo posterior, publicado nos Annales (1971). Para um trabalho recente que procura demonstrar como Lévi-Strauss se reaproximou da história, ver IEGELSKI 2012, p. 248-280. 
seria "fundamentalmente descritiva", ou seja, não teórica. Tal crítica, contudo, pode ser questionada. A ênfase do manifesto de 1958 recai a todo momento na "dialética da duração", na "pluralidade" dos tempos históricos (BRAUDEL 1978a, p. 43), e não apenas na longa duração. Estrutura é tomada como um conceito analítico, não como um termo descritivo, e como tal, como constructo analítico, contrapõe-se e se articula dialeticamente ao conceito de evento.

Daqui derivam o segundo e o terceiro pontos que gostaríamos de ressaltar: como, por um lado, Braudel conceitua a estrutura e, por outro, como apreende suas relações dialéticas com o evento. Estrutura é "articulação, arquitetura, porém mais ainda, uma realidade" de natureza temporal, isto é, com duração própria. Estruturas surgem e desaparecem conforme seus ritmos descontínuos. Inexistem, assim, estruturas anistóricas, para sempre imutáveis, como propusera a antropologia estrutural de Lévi-Strauss. As estruturas - sempre históricas, afirma o historiador - são "sustentáculos e obstáculos" (BRAUDEL 1978a, p. 49-50). Nesta formulação rapidamente tornada canônica, Braudel dialogou explicitamente com toda a tradição crítica, vinda do pensamento oitocentista, que tratou da dialética liberdade/necessidade. Como "sustentáculos e obstáculos", as estruturas temporais de longa duração estabeleceriam a cada circunstância historicamente dada o horizonte do possível, isto é, a partir do que foi legado do passado, o que se poderia fazer em um determinado espaço de atuação humana. Quando algo se passou no plano de eventos que se adensaram cumulativamente ultrapassando esse horizonte do possível, já se tratava de uma estrutura em processo de transformação. Ao partir para a exemplificação do que seriam essas estruturas, Braudel fugiu deliberadamente do campo que Ihe era mais confortável (a geohistória do Mediterrâneo ou a economia-mundo capitalista europeia), justamente para fundamentar a validade geral de seu argumento. Não será sem surpresa que um leitor atual, desavisado por décadas de difusão do que seria a longa duração em Braudel, o encontrará citando a análise de Pierre Francastel (1993) sobre o espaço pictórico geométrico criado 
pelo Renascimento florentino como um exemplo de estrutura de longa duração. Trata-se de uma teorização de estrutura aberta tanto às forças econômicas e sociais como às forças simbólicas, bastante próxima ao trabalho que seria posteriormente realizado pelo antropólogo Maurice Godelier (1986) sobre as determinações recíprocas do mental e do material.

Outro diálogo surpreendente - o terceiro e último ponto a ressaltar - se encontra no tratamento das relações entre estrutura e evento. O evento pertence à escala da curta duração, é certo, mas Braudel reconhece o peso do argumento dos "filósofos" de que "um evento, a rigor, pode carregar-se de uma série de significações ou familiaridades. Dá testemunho por vezes de movimentos muito profundos e, pelo jogo factício ou não das 'causas' e dos 'efeitos' caros aos historiadores de ontem, anexa um tempo muito superior à sua própria duração". Tal conceituação faz parte, nas palavras de Braudel (1978a, p. 45), desse "jogo inteligente e perigoso que as reflexões recentes de Jean-Paul Sartre propõem". Abria-se, assim, um diálogo direto com o outro grande crítico contemporâneo da antropologia estrutural anistórica de Lévi-Strauss. A referência a que se remete Braudel é justamente a "Questão de Método", publicada em 1957. O que haveria de "perigoso" no jogo proposto por Sartre? Ver, na singularidade universal do indivíduo, na trama dos eventos particulares passados e presentes que marcam a vida de cada um nós, as múltiplas articulações de escalas espaço-temporais bem mais vastas, ou seja, estruturais. Mas, não somente isto: para apreender a totalidade no acontecimento, valer-se do método progressivoregressivo, isto é, do permanente jogo de "vaivém" (a expressão é de Sartre) que percorre o circuito hermenêutico completo do todo à parte / da parte ao todo; do abstrato ao concreto / do concreto ao abstrato; do presente ao passado / do passado ao presente; da biografia à época / da época à biografia (SARTRE 1978 , p. 170). Exercício perigoso, porém inteligente e, para Braudel, inegavelmente sedutor:

a cada vez, o estudo do caso concreto - Flaubert, Valéry, ou a política exterior da Gironda - reconduz, finalmente, Jean- 
Paul Sartre ao contexto estrutural e profundo. Essa pesquisa vai da superfície às profundezas da história e atinge minhas próprias preocupações. Alcançá-las-ia ainda melhor se a ampulheta fosse inclinada nos dois sentidos - do evento para a estrutura, depois das estruturas e dos modelos para o evento. (BRAUDEL 1978a, p. 75).

Aberturas ao campo do biográfico, do político, da história cultural, do marxismo, do existencialismo, tudo em nome da melhor captura da dialética da duração e da pluralidade dos tempos históricos: o antidogmatismo de Braudel, lido por seus críticos como um ecletismo teoricamente pouco sólido (FONTANA 1998, p. 208-211), permitiu-Ihe igualmente estender a mão aos que haviam dado suporte intelectual aos seus algozes de 1940 a 1945 . No rodapé seguinte à citação de Francastel, lemos o nome do historiador Otto Brunner como um exemplo de história social, fora da França, atento à escala da longa duração (BRAUDEL 1978a, p. 51, n. 13). Em 1959, Braudel se deteve mais longamente sobre o trabalho desse pesquisador, ao veicular nos Annales um ensaio sobre o livro Novas formas de história social, que Brunner havia publicado na Alemanha em 1956. Brunner nascera em Viena, em 1889, onde fez toda sua formação de historiador e se tornou professor. Após a $2^{\text {a }}$ Guerra Mundial, foi afastado da direção do Instituto Austríaco de Pesquisa Histórica por suas filiações institucionais e afinidades ideológicas ao nazismo. Em 1954, foi contratado como catedrático pela Universidade de Hamburgo, onde veio desempenhar papel crucial na renovação historiográfica alemã, até aposentar-se em 1968 (OLSEN 2012, p. 138-139).

Braudel procurou dar conta, em sua resenha, da especificidade do programa de história social proposto por Brunner, que, em associação com Werner Conze, da Universidade de Heidelberg, estava então formalizando as bases de uma nova Strukturgeschichte - ou seja, de uma História Estrutural (IGGERS 1983, p. 262-264). Braudel não escondeu seu incômodo em relação ao livro, que nada devia em sua gênese aos Annales. No entanto, era exatamente isso o que o atraía no volume, pois, vindo de uma outra tradição intelectual e historiográfica, ele oferecia, "nas águas da longa duração, um certo modelo 
particular da história social europeia, do século XI ao XVIII" (BRAUDEL 1978b, p. 164). Um dos aspectos mais criticados por Braudel foi exatamente o tratamento imóvel desse longo arco de tempo, sem atentar para as múltiplas modulações do tempo histórico. Ele também expressou um claro desconforto com o elogio de Brunner à estabilidade social do mundo do Antigo Regime; confessou não ter entendido a proposta de se analisar a história social do passado nos termos dos horizontes conceituais coevos; criticou a ausência de distinção entre história social e história política. Braudel, contudo, "dividido entre uma certa simpatia e algumas reticências bastante vivas" (BRAUDEL 1978b, p. 175), finalizou com um aceno para o diálogo entre duas tradições historiográficas distintas que buscavam atingir o mesmo alvo de compreender a história estrutural na longa duração e de forma interdisciplinar.

O chamado à conversa foi atendido. Em 1961, Conze, que já havia resenhado elogiosamente $O$ Mediterrâneo quando de sua primeira edição, convidou Braudel para um ciclo de conferências em Heidelberg, no que pode ser tomado como um momento de inflexão na trajetória de Reinhart Koselleck. Deixamos o autor ao ser libertado do campo soviético no Cazaquistão, em 1946. Ao regressar à Alemanha, Koselleck retomou o quanto antes seus estudos, ingressando na Universidade de Heidelberg, onde, em 1954, sob a orientação do historiador Johannes Kühn e a inspiração teórica de Martin Heidegger, Hans-Georg Gadamer e, sobretudo, Carl Schmitt, defendeu sua primeira tese de doutorado, Crítica e Crise, um sofisticado estudo sobre as relações contraditórias entre o Absolutismo e o Iluminismo, e a gênese da permanente situação de crise da modernidade burguesa pós-Revolução Francesa (KOSELLECK 1999). A avaliação crítica do legado do Iluminismo, que, em razão de suas filosofias da história de fundo utópico, converteu-se em um elemento de permanente desestabilização política, fez parte da tentativa de Koselleck de dar conta de suas experiências pessoais traumáticas entre 1934 e 1945. De fato, como ele próprio reconheceu em diversas ocasiões, toda sua produção intelectual seria movida por esse impulso básico (OLSEN 2012). 
Braudel, contudo, só entrou no radar de Koselleck na sua segunda tese de doutorado (sua Habilitationsschrift), agora sob a supervisão de Werner Conze. Entre um trabalho e outro, mudou não somente o orientador (Kühn se aposentou em 1957) como também o recorte cronológico (dos séculos XVII e XVIII para o século XIX), o recorte espacial (de Inglaterra e França para a Prússia) e o subcampo disciplinar (da história intelectual para a história social). Ao ser contratado como catedrático em Heidelberg, em 1957, Conze, outro antigo simpatizante nazista às voltas com um permanente acerto de contas com o passado, imediatamente lançou, em associação com Otto Brunner, as bases do programa da História Estrutural. Seu fundamento consistia em romper com as tradições historicistas alemãs por meio de um mergulho nas abordagens de larga escala e na aliança com as ciências sociais adjacentes (notadamente com a sociologia). Eram justamente essas afinidades eletivas que atraíam Braudel - conforme deixou claro na resenha de 1959 -, e que o levaram a ser convidado por Conze para visitar Heidelberg, no exato momento em que Koselleck elaborava sua tese de Habilitation.

Prússia entre a Reforma e a Revolução (1791-1848), defendida em 1965 e publicada dois anos depois (infelizmente, ainda sem tradução para o português), representou uma primeira aproximação analítica de Koselleck em relação à pluralidade dos tempos históricos, explorada para lidar com a especificidade social e política prussiana no século XIX, travejada, por um lado, pela aceleração das transformações sociais e econômicas advindas do engate industrial e, por outro, pelas assimetrias temporais contidas no dilema reforma versus revolução. Em seus termos, "teoricamente, a investigação trata de diferentes estratos de tempos. As distintas durações, velocidades e modos de aceleração desses estratos produziram as tensões da época e, assim, caracterizaram sua unidade" (apud OLSEN 2012, p. 142).

Essa abordagem, combinada a uma reavaliação dos legados intelectuais de Schmitt, Heidegger e Gadamer, propiciou as bases intelectuais para as contribuições de Koselleck sobre a 
história conceitual do universo de fala germânica entre 1750 e 1850. O projeto, coordenado de forma conjunta com Brunner e Conze, com desdobramentos em várias historiografias nacionais, resultou em nove volumes publicados entre 1972 e 1997. Foi no âmbito desse empreendimento coletivo que se deu a construção teórica de Koselleck sobre a dialética dos tempos históricos. A partir de 1973, quando passou a trabalhar na recém-criada Universidade de Bielefeld, Koselleck abriu outro diálogo crítico, agora com a história social de matriz weberiana proposta por Hans-Ulrich Wehler e Jürgen Kocka, seus colegas de instituição. Todos os trabalhos de Koselleck sobre o problema dos tempos históricos publicados nas décadas de 1970 e 1980, grande parte dos quais reunidos nos volumes Futuro Passado (2006) e Estratos do Tempo (2014), podem ser igualmente lidos como uma crítica direta às teorias da modernização que embasaram o programa de História Social de Wehler e Kocka (IGGERS 1997, p. 65-77; ELEY 2005, p. 65-81; OLSEN 2012, p. 203-267).

Diferentemente de Braudel, cuja reflexão teórica mais detida sobre a problemática dos tempos históricos se resume basicamente ao artigo de 1958, a elaboração de Koselleck encontra-se dispersa em vários dos capítulos que compõem os livros Futuro Passado e Estrados de Tempo. Assim como fizemos para o historiador francês, cabe aqui apenas uma apresentação sumária dos principais eixos da teoria koselleckiana sobre a pluralidade dos tempos históricos, ressaltando em que medida ela deu continuidade às formulações braudelianas e em que medida trouxe inovação a tais formulações.

O ponto fundamental repousa sobre o que Koselleck denominou como a "indigência teórica da ciência da história", título de um artigo publicado originalmente em 1972. Ao retomar o argumento popperiano sobre a perda de sentido da oposição entre ciências nomotéticas e idiográficas, Koselleck ressaltou a necessidade de a prática de pesquisa dos historiadores se fundar em teorias explícitas, "aceitando o desafio de uma exigência de teoria se quisermos que a ciência da história continue a se definir como ciência". Os "teoremas das ciências vizinhas" - isto é, a 
aposta na interdisciplinaridade feita, dentre outros, pelos Annales e pela história social alemã - não poderiam vir em socorro. Para Koselleck (2014, p. 280), "a ciência da história, disposta ubiquitariamente, só poderá persistir como ciência se desenvolver uma teoria dos tempos históricos, sem a qual a ciência da história, como investigadora de tudo, se perderia na infinidade". A saída para suplantar a situação de "indigência teórica", portanto, seria renovar e radicalizar a perspectiva braudeliana.

A primeira inovação em relação a Braudel consistiu em fundamentar a elaboração teórica em torno das categorias metahistóricas da experiência e da expectativa. Segundo Koselleck, elas permitem dar conta, de forma integrada e substantiva, de como, em um determinado presente, se articulam as dimensões temporais do passado e do futuro. No que se refere à categoria da experiência, a definição koselleckiana aponta tanto para a "elaboração racional" como para as "formas inconscientes de comportamento" presentes nas múltiplas experiências dos atores históricos. A experiência que guia o horizonte das expectativas para o futuro, conformando a atuação planejada - ou não - em um dado presente, "é espacial, porque ela se aglomera para formar um todo em que muitos estratos de tempos anteriores estão simultaneamente presentes, sem que haja referência a um antes e um depois". Se, no desenrolar dos acontecimentos, as expectativas confirmam as experiências prévias, esses "eventos estruturados" não rompem o legado dos estratos de tempo anteriores. Apenas aquilo que não é esperado, mas que está necessariamente contido no campo de possibilidades construído pelo passado, cria uma experiência nova, alargando assim o horizonte de expectativas (KOSELLECK 2006, p. 311-313).

As relações entre espaços de experiências e horizontes de expectativas, ressalta, não são estáticas. A tese central de Koselleck sobre a temporalidade específica da modernidade consiste justamente em assinalar o hiato crescente entre o achatamento dos espaços de experiências e o alargamento dos horizontes de expectativas, algo que se relaciona à própria 
transformação do conceito de história na virada do século XVIII para o XIX. A percepção de que o tempo sempre marcha para frente, em um sentido unívoco de progresso contínuo, forneceu, daquele momento em diante, um dos mais sólidos fundamentos para a construção dos saberes históricos. No entanto, o descompasso crescenteentreexperiência expectativa produzido pela aceleração progressiva do tempo histórico também possibilitou a tomada de consciência de que o tempo presente é sempre atravessado por múltiplos e diferentes tempos passados. A constatação empírica da "contemporaneidade do não contemporâneo", em realidade, antecedeu em pelo menos um século e meio a obra dos historiadores pós-2 ${ }^{a}$ Guerra Mundial (KOSELLECK 2006, p. 14). A partir dessas duas categorias meta-históricas básicas, experiência e expectativa, Koselleck fundamentou o tratamento teórico e empírico dos estratos do tempo.

Braudel foi frequentemente criticado por supostamente ter sido incapaz de articular, na sua prática historiográfica, as inter-relações entre os três tempos - estrutura, conjuntura, acontecimento - que descreveu e teorizou (HEXTER 1972, p. 532-33; REIS 2003, p. 119; FONTANA 1998, p. 208). Koselleck foi um dos que assinalou esse problema: o modelo de Braudel, malgrado sua notável inovação ao teorizar a existência de temporalidades múltiplas, com frequência induziu - e não raro os esforços e ressalvas de seu próprio autor - ao equívoco de se compreender a longue durée como um ente estático (DUTT 2015, p. 316) e as diferentes durações como "circuitos paralelos", estanques entre si (KOSELLECK 2014, p. 13). Para resolver o impasse, o historiador alemão concentrou-se no par interligado estrutura/evento $e$, ao incorporar integralmente a crítica de Braudel ao tratamento estático que Otto Brunner dera ao tempo estrutural, conferiu-Ihe uma plasticidade temporal mais acentuada, enxergando um campo de integração entre a repetibilidade e a singularidade, cuja trama caberia ao historiador decifrar em sua prática de pesquisa. Dessa maneira, Koselleck simultaneamente condensou e complexificou a abordagem braudeliana:condensou, pois propiciou as bases para se pensar as formas objetivas como aspectos remissíveis a durações variadas 
de um tempo estrutural que se combinam nas experiências humanas; complexificou, pois forneceu mais elementos para se articular estruturas, processos e sincronismos.

A característica essencial das estruturas, para o historiador alemão, seria a reiteração temporal, "o retorno do mesmo, ainda que o mesmo se altere a médio ou longo prazo" (KOSELLECK 2014, p. 305). Em Koselleck e à exemplo de Braudel, as estruturas têm real historicidade e envolvem de forma mais explícita os diversos domínios do mental e do material, o que abre espaço para um diálogo construtivo entre a história dos conceitos e a história social de vezo marxista. Dentre os exemplos de estrutura que fornece, incluem-se os "modelos constitucionais, [...] as forças produtivas e as relações de produção, [...] as circunstâncias geográficas e espaciais, [...] formas de comportamento inconscientes, [...] sucessão natural de gerações, [...] os costumes o os sistemas jurídicos", dentre outros (KOSELLECK 2006, p. 136). O autor discerne as estruturas diacrônicas de eventos (feixe de acontecimentos que constituem uma trama processual envolvendo amplos movimentos e transformações de ordem econômica e política) das estruturas de prazo mais longo (ideias, costumes, normas de conduta, práticas econômicas e sociais que transcendem em muito as experiências individuais). O passo adiante em relação às concepções braudelianas de conjuntura e longa duração está na elucidação de sua relação complexa, dialógica e movediça com as experiências individuais, que são ao mesmo tempo únicas e remissíveis a uma certa ancestralidade e repetibilidade. É nesse sentido que as experiências do tempo podem ser percebidas em estratos, sendo que "eventos e estruturas estão entrelaçados, mas um nunca pode ser reduzido ao outro" (KOSELLECK 2014, p. 307).

Dessa forma, o tratamento da dimensão temporal do evento é igualmente mais complexo do que em Braudel, mas as linhas de continuidade são evidentes. A começar pelo pressuposto geral: "estruturas mais ou menos duradouras, mas de todo modo de longo prazo, são condições de possibilidade para os 
eventos [;] [...] "ambos os níveis [...] remetem um ao outro, sem que um se dissolva no outro." De fato, e aqui vemos o giro da ampulheta braudeliana, "certas estruturas só podem ser apreendidas nos eventos nos quais se articulam e por meio dos quais se deixam transparecer". "A forma mais adequada para se apreender o caráter processual da história moderna", conclui Koselleck, "é o esclarecimento recíproco dos eventos pelas estruturas e vice-versa" (KOSELLECK 2006, p. 137-140). Certos eventos, ao trazerem ruptura na ordem de repetição do tempo, adquirem claro significado estrutural; reversivamente, determinadas durações não imediatas podem se tornar eventos. Ademais, a temporalização da história ocorrida na virada do século XVIII-XIX com a chamada "dupla revolução" (Koselleck esposa, sem citá-lo, o conceito cunhado por Eric Hobsbawm [1962] 1977) modificou a natureza das inter-relações entre estruturas e eventos. Com a aceleração do tempo histórico que se deu em seu esteio, "a própria mudança estrutural passou a ser um evento: esta é a característica da nossa modernidade" (KOSELLECK 2014, p. 307). Para dizer de outra forma: uma das principais manifestações da aceleração do tempo histórico da modernidade reside justamente no fato de as estruturas históricas serem de duração cada vez mais curta.

O olhar cuidadoso para as profundas rupturas históricas trazidas pela permanente revolução capitalista das forças produtivas, das relações de produção, dos meios de transporte e de comunicação também levou Koselleck a rediscutir a natureza do tempo geográfico. Braudel foi fundamentalmente um historiador do mundo pré-industrial, sentindo-se desconfortável com a análise do mundo produzido pela Revolução Industrial (DUTT 2015, p. 321). Koselleck navegou bem pelos dois, o que facilmente se nota pela conceituação que deu aos estratos do tempo. Para além das estruturas e dos eventos, reconheceu a existência de "precondições que podem ser delimitadas geográfica ou biologicamente e cuja duração escapa à intervenção humana". Braudel conceituaria essa dimensão como parte da "Ionguíssima duração". Koselleck (2016, p. 73-89) nos fornece outra solução teórica, 
ao chamar atenção para a distinção temporal de fundo entre as "condições espaciais meta-históricas", isto é, aquelas condições que escapam integralmente ao domínio humano e, portanto, estabelecem-se como determinação geográfica, e os "espaços históricos da organização humana", isto é, os espaços físiconaturais historicamente transformados pela ação humana e, portanto, submetidos às mesmas variações temporais de outras estruturas históricas. Se a Revolução Neolítica permitiu o início da apropriação em larga escala dos recursos físico-naturais, os espaços históricos da organização humana continuaram a enfrentar um obstáculo intransponível, ditado pelos limites que as forças animal e eólica imprimiam à velocidade. No mundo reconfigurado pela ciência e pela técnica industriais, a aceleração adquiriu a capacidade de modificar radicalmente as relações espaço-temporais, desnaturalizando o espaço geográfico e, por consequência, as condições espaciais meta-históricas.

Para resumir em uma frase o argumento que procuramos expor até aqui: o maior e melhor continuador da teorização braudeliana dos tempos históricos, que dele partiu e que foi mais além, não se encontra na França, mas sim na Alemanha. É notável, contudo, o silêncio dos especialistas sobre essas relações de fundo entre Braudel e Koselleck, o que talvez traduza sua recepção predominante como o historiador dos conceitos, que deixa de lado o historiador atento à vida social e material. As ótimas introduções que Elias Palti (2001), Marcelo Jasmin (2006), Arthur Alfaix Assis e Sérgio da Mata (2013) prepararam para edições em espanhol e português das obras do historiador alemão reforçam o que estamos afirmando: nenhuma palavra sobre Braudel e os tempos históricos, todas as atenções são direcionadas para as tradições da história intelectual alemã com as quais dialogou Koselleck. Observação parecida vale para a historiografia anglo-saxã, que ainda tem que lidar com uma barreira no campo da recepção teórico-conceitual: a edição em inglês de Estratos do Tempo (KOSELLECK 2002), feita sob a coordenação de Hayden White, traduziu "teoria dos tempos históricos" como "teoria de periodização!" No entanto, mesmo o autor que identificou esse problema, o historiador 
norueguês Helge Jordheim (2012), oferece-nos apenas uma menção a Braudel em um artigo que lida exatamente com a teoria das múltiplas temporalidades de Koselleck. Não é difícil enxergar, por fim, uma série de aproximações entre a obra de Koselleck e o historicismo realista de Antonio Gramsci. Esteve Morera (1990, p. 105) explicitou essas relações para Braudel; o mesmo pode ser feito com o corpus koselleckiano. Explorar as articulações teóricas entre Braudel, Koselleck e o historicismo realista de fundo marxista constitui objeto para outra ocasião, ou seja, para um livro de fôlego.

A teorização sobre os tempos históricos que até aqui examinamos foi concebida por seus autores como sendo de caráter eminentemente prático, voltada para as demandas concretas da investigação histórica. Dado esse caráter, quais são suas implicações e potencialidades para o estudo da escravidão moderna? Como nos valer dessas perspectivas para a compreensão desse objeto específico? No espaço que nos resta, pretendemos apontar os ganhos a serem obtidos, caso a historiografia da escravidão moderna abrace a proposta braudeliana/kosellekiana de tratamento da dialética dos tempos históricos. Para tanto, efetuaremos um breve balanço historiográfico de algumas das principais tendências do campo da escravidão para, em seguida, apresentarmos nossa acepção da dialética dos tempos da escravidão moderna sob um olhar braudel-koselleckiano. Nossa intenção não é cobrar dos estudiosos do passado formulações, definições e conclusões que são caras ao nosso enfoque e não aos deles, mas antes mapear o terreno para um campo de possibilidades analíticas ainda em aberto.

\section{Os múltiplos tempos da escravidāo negra nas Américas}

Sem negar as contribuições das diferentes gerações de historiadores ou projetar sobre o trabalho deles um leque alheio de preocupações, efetuaremos, agora, uma avaliação panorâmica - e, portanto, necessariamente sintética - sobre a forma como 
cinco das principais correntes da historiografia sobre a escravidão negra das Américas lidaram com o tempo histórico.

Essa historiografia é herdeira direta do movimento abolicionista anglo-saxão e francês da virada do século XVIII para o XIX (STEPHEN 1830; WALLON 1847). As primeiras histórias da escravidão antiga e moderna foram compostas por letrados e ativistas políticos antiescravistas que, para melhor combater a instituição, viram-se obrigados a historiá-la (FINLEY 1991, p. 13-68). Os abolicionistas o fizeram dentro e a partir do que Koselleck denominou a "temporalização da utopia", a saber, a projeção para o futuro de um mundo ideal vislumbrado no presente (o mundo da liberdade) - somente o aperfeiçoamento moral e institucional vindouro romperia com as misérias daquele presente (KOSELLECK 2014, p. 121-138). Desde seu nascimento, portanto, a escrita da história da escravidão negra fundou-se nas premissas temporais do conceito de progresso: o avanço econômico, moral e humano a ser obtido com a abolição é o que justificaria o combate sem quartel à instituição (DAVIS 1984, p. 107-116).

Não obstante todas suas revisões e renovações, em grande parte a historiografia no século XX manteve, ao examinar esse objeto específico, as linhas gerais da concepção de tempo linear e progressiva adotada pelos seus primeiros estudiosos, os abolicionistas do século XIX. Vejamos, primeiramente, historiadores de inspiração marxista. Dois de seus pioneiros, Eric Williams (2012) e C. R. L. James (2000), tiveram como eixo central de crítica a perspectiva veiculada por Reginald Coupland (1964), que reforçou, no centenário da abolição britânica, a autoimagem congratulatória que os abolicionistas haviam criado de sua façanha, uma empresa moral apartada de quaisquer interesses materiais, compromissada apenas com o aperfeiçoamento humano. Coupland era, então, um dos principais ideólogos do império britânico: atacar sua explicação da abolição, fundada na premissa de que a Grã-Bretanha era uma agente primordial do progresso civilizacional, significava atacar os fundamentos ideológicos do império que Williams e 
James estavam a combater. Ambos desenvolveram a tese, já presente em Marx, de que a escravidão colonial nas Américas foi crucial para a emergência do capitalismo industrial no espaço metropolitano, mas as forças econômicas, sociais e políticas que emergiram com a consolidação da industrialização acabaram por solapar as bases da escravidão nas colônias. A constelação histórica das forças capitalistas se modificara na passagem da era mercantilista para a era do livre comércio, mas a escravidão negra permanecera igual.

Williams e James, assim, operaram com a mesma conceituação do tempo histórico da escravidão negra que fora adotada por Coupland, ou seja, um tempo uniforme do século XVI ao século XIX. Como sabemos, a análise do historiador brasileiro Fernando Novais (1979) sobre o papel da escravidão negra na estrutura e dinâmica do Antigo Sistema Colonial fundou-se, em larga escala, no esquema explicativo de Eric Williams. Ainda que seja possível identificar a dialética braudeliana dos tempos históricos nos escritos de Novais, em função das especificidades de seu objeto e de sua filiação em relação ao trabalho de Williams, ele não se debruçou sobre a pluralidade temporal da escravidão colonial. Para autores como Eugene Genovese (1976), Moreno Fraginals (1987) e João Manuel Cardoso de Mello (2009), que lidaram com o século XIX com lentes teóricas semelhantes às de Novais, o prolongamento da escravidão negra seria uma manifestação "tardia", porém contínua, de seu caráter colonial e periférico, destinada a entrar em crise definitiva em lugares como Estados Unidos, Cuba e Brasil, na medida em que as forças produtivas do arranque industrial a colocavam localmente em xeque. Tal foi, também, o tempo da escravidão na elaboração teórica do conceito do "modo-de-produção escravista colonial" (CARDOSO 1973; GORENDER 2010); tal é o tempo da escravidão nos trabalhos dos autores brasileiros atuais que operam conforme o modelo do que chamam de "Antigo Regime nos Trópicos" (GUEDES 2008; FRAGOSO 2013).

Em uma chave analítica divergente dessa que acabamos 
de ver, a New Economic History se encarregou de questionar empiricamente os argumentos que postularam a irracionalidade econômica da escravidão negra e sua suposta incompatibilidade com o mundo criado pela Revolução Industrial. Voltados sobretudo à análise da escravidão no século XIX, Robert Fogel e Stanley Engerman (1974) procuraram demonstrar a eficiência superior do trabalho escravo em relação ao trabalho livre na agricultura norte-americana; Seymour Drescher (1977) reviu os números de Eric Williams sobre a crise econômica do Caribe britânico na virada do século XVIII para o XIX; David Eltis (1987) ampliou as conclusões desses historiadores, ao examinar o crescimento econômico de Brasil e Cuba na primeira metade do século XIX, fundado no tráfico negreiro da era industrial. Essa agenda guiou igualmente as investigações de Pedro Carvalho de Mello e Robert Slenes (1980) sobre os anos finais da cafeicultura escravista do centro-sul do Império do Brasil. Se a escravidão caminhava bem na esfera econômica, por que ela desapareceu? A resposta deveria ser buscada na esfera política, isto é, na novidade da mobilização antiescravista. O interessante a se registrar, no entanto, é o tratamento do tempo histórico: para os historiadores que esposaram o quadro analítico da New Economic History, a escravidão, como um sistema racional de alocação de recursos (no caso, a propriedade em seres humanos), obedeceria a uma lógica econômica atemporal (TOMICH 2016). O que tem uma temporalidade específica é o abolicionismo, mas ela é guiada pelas transformações nas noções de progresso moral, apartadas de interesses econômicos imediatos. A cisão entre o econômico e o político nos traz de volta, assim, a uma conceituação do tempo histórico da escravidão negra nas Américas bastante próxima à adotada pelas duas primeiras vertentes citadas anteriormente.

Cabe um espaço adicional aos estudos correntes sobre o abolicionismo, que constituem uma quarta vertente e que têm nas obras de David Brion Davis $(1988 ; 1999)$ e Seymour Drescher (2009) suas referências matriciais. O próprio título da obra clássica de Brion Davis, O problema da escravidão na cultura ocidental, de 1966, traduz a acepção de tempo que a embasa. Haveria uma linha de continuidade secular 
na escravidão moderna, dada pelas formas de justificativa ideológica e exploração econômica do trabalho escravo, independentemente dos poderes coloniais que o mobilizaram. $\mathrm{O}$ que mudou foi a cultura ocidental e o locus dessa transformação se encontrava no universo anglo-saxão. No livro seguinte, sobre o problema da escravidão na Era das Revoluções, David Brion Davis relacionou a transformação ideológica que gerou a força política abolicionista britânica às tensões sociais e culturais produzidas pela Revolução Industrial. Drescher, ainda que crítico de Brion Davis, esposou seu enquadramento temporal a respeito da escravidão e do abolicionismo, ao afirmar que o aspecto central para a compreensão da gênese e do sucesso do antiescravismo reside na novidade da sólida esfera pública britânica, fundada no ideário de uma liberdade tipicamente britânica. Capaz de mobilizar e influenciar as políticas governamentais domésticas e, por conseguinte, as diretrizes de sua política externa, o movimento abolicionista espalhou-se da Grã-Bretanha pelo mundo, como em um efeito dominó (DRESCHER 2009). A persuasão historiográfica desse argumento pode ser aquilatada pelo livro recente de Angela Alonso, que, ao tratar da história do movimento abolicionista brasileiro, emprega diretamente a metáfora do "dominó" como nexo explicativo (ALONSO 2015, p. 27).

O complemento aos historiadores que explicam a abolição pela capacidade de mobilização política do movimento antiescravista se encontra nos trabalhos que tomam os escravos como os agentes de sua própria liberdade. Há algumas variantes nessa vertente, como impressa no trabalho mais maduro de Emília Viotti da Costa, que buscou combinar no movimento de análise as contradições entre metrópole e colônia, a agenda abolicionista e as ações transformadoras promovidas pelos próprios escravos (1998). Todavia, o mais frequente é a ênfase unidimensional no protagonismo escravo. A Nova História Social da escravidão, que deitou raízes nos Estados Unidos no contexto de luta pelos direitos civis (GENOVESE 1974; GUTMAN 1976), e no Brasil (LARA 1988; CHALHOUB 1990; MACHADO 1994), no período da redemocratização e de 
efervescência do movimento negro, teve o mérito incontestável de olhar além do jugo senhorial e enquadrar os escravos como sujeitos históricos plenos. O problema é que noções caras a tal vertente historiográfica, como agência e protagonismo escravo, embebidas que estão no pensamento liberal, podem exagerar a potência transformadora dos indivíduos, obscurecendo outros aspectos fundamentais da realidade escravista, como condicionantes de ordem econômica e política (JOHNSON 2003; ALADREN 2009; PIQUERAS 2016). Mais do que isso, tais noções tendem a construir a imagem de uma história na qual os escravizados agem sempre conforme uma lógica única, universal e atemporal, da busca incessante pela liberdade, não importando o contexto em que atue, e que, ao fim e ao cabo, destruirá a escravidão.

É certo que essas cinco vertentes que muito brevemente descrevemos registram inflexões, mudanças e rupturas, mas elas variam basicamente entre 0 episódio e a conjuntura. 0 que prevalece é a impressão de uma unidade temporal do início do século XVI ao final do século XIX. Nesses termos, inflexões, mudanças e rupturas estão fora do que constitui a essência da relação escravista, que, por sua vez, é sempre a reiteração de um mesmo. Em todos esses casos, no século XIX a escravidão seria uma instituição fadada à destruição, seja em razão do avanço das forças produtivas, da mobilização abolicionista ou da ação dos escravos. Há, ainda, outro ponto de convergência em parte da produção historiográfica que sumariamos. Parcela considerável da historiografia da escravidão posterior à $2^{a}$ Guerra foi modulada, de um modo ou de outro, pelas formas de conceituação do tempo histórico empregadas em distintas manifestações das teorias da modernização, dentre as quais a mais forte, sem dúvida, consiste em tomar a trajetória ocidental na direção de uma sociedade racionalista, democrática, individualista e industrial como o caminho inevitável do desenvolvimento histórico, e a GrãBretanha como a manifestação pioneira e acabada dessa senda.

A teoria da pluralidade dos tempos históricos apresentada 
na primeira parte deste artigo fornece uma resposta possível para resolver tais problemas. Foi ela, por exemplo, que inspirou Dale Tomich (2011) na proposição da categoria da Segunda Escravidão como uma ferramenta para reenquadrar o problema da escravidão negra no século XIX. A partir de um engajamento crítico com a perspectiva analítica do sistema-mundo - que, como se sabe, tem na teoria braudeliana dos tempos históricos um de seus principais lastros -, Tomich interveio no debate entre o marxismo e a New Economic History apontando para a transformação que a escravidão do Novo Mundo sofreu na passagem do século XVIII para o XIX. Nota-se, em especial, o uso bastante imaginativo da teoria dos tempos históricos de Koselleck para tentar solucionar o impasse a que levou o debate de Seymour Drescher com a tese de Eric Williams (TOMICH 2011, p. 122-150). O foco de Tomich consiste em assinalar as profundas descontinuidades espaço-temporais da escravidão oitocentista: sob o manto de uma aparente continuidade, o que se observa no arranque escravista de Brasil, Cuba e Estados Unidos é uma profunda reconfiguração sistêmica da instituição. Tratar-se-ia de uma nova escravidão, de uma Segunda Escravidão, ou seja, de uma nova temporalidade.

O elemento mais sedutor dessa proposta reside, no nosso ponto de vista, não necessariamente na descrição que Tomich nos oferece das fronteiras mercantis açucareiras de Cuba em comparação com as antigas zonas produtoras de colônias como Jamaica, Martinica e Guiana inglesa (tal é a área de concentração de suas pesquisas empíricas), mas no olhar teórico que propõe para reconceituar a escravidão a partir de seus múltiplos estratos de tempo. A partir desse olhar, integralmente atinado à exposição da primeira parte deste texto, podem-se descortinar outros aspectos importantes da pluralidade dos tempos históricos da escravidão, como aliás vários historiadores vêm fazendo, no exterior e aqui no Brasil (para um balanço abrangente, ver MARQUESE; SALLES 2016). Tal mirada permitiu dar conta do jogo de estruturas e eventos presentes na produção, na reprodução e na crise das múltiplas eras da escravidão negra nas Américas (MARQUESE; PARRON; 
BERBEL 2016; SCHMIDT-NOWARA 2011; BLACKBURN 2011; DAL LAGO 2012); da articulação contraditória entre a novidade do antiescravismo britânico e o avanço das fronteiras mercantis da escravidão atlântica no século XIX (FRADERA; SCHMIDTNOWARA 2013; FERRER 2014; PARRON 2015; MARQUES 2016; YOUSSEF 2016); dos tempos distintos das normas e práticas jurídicas que travejaram a escravidão ibérica, cubana e brasileira (SILVA JR. 2013; 2015; SOUZA 2017); das trajetórias globais de commodities específicas (BECKERT 2014; MARQUESE 2013); da diversidade regional de zonas escravistas particulares (SALLES 2008; PIQUERAS 2011; CHALHOUB 2012; SANTOS 2012; MORENO 2013; BAPTIST 2014; MUAZE; SALLES 2015; SANTOS 2016; ROOD 2017; FERRARO 2017; BARROSO; LAURINDO JR. 2017).

É necessário, contudo, ir adiante. A estrutura histórica da escravidão oitocentista - a Segunda Escravidão, na concepção original de Tomich - foi de mais curta duração. Esse "encurtamento" de uma estrutura histórica vinculada ao mundo industrial poderá vir a ser conceituado de modo inovador a partir das observações de Koselleck sobre a natureza da aceleração do tempo histórico oitocentista. Há boas pesquisas sobre o impacto da adoção do tempo do relógio sobre a vida escrava no regime de plantation (SMITH 1997; ROBERTS 2013, p. 26-79); poderemos avançar nesse caminho com investigações que articulem o emprego em larga escala dos modernos instrumentos técnicos de aceleração criados pelo capitalismo industrial ao aumento da exploração do trabalho escravo e à crise global da Segunda Escravidão. A aceleração do tempo histórico produziu uma convergência crescente entre a política doméstica e a política externa na arena mundial: os trabalhos recentes de Tâmis Parron (2015), Matthew Karp (2016), Keila Grinberg (2016), Gabriel Aladrén (2017) e Beatriz Mamigonian (2017) indicam o quão promissor é o tema da geopolítica da escravidão, sobretudo quando casado à análise dos eventos produzidos pelos conflitos entre senhores, escravos e sujeitos livres subalternos. A geohistória da escravidão do Novo Mundo - o que inclui as chamadas 
trocas colombianas - é outro campo que merece ser reaberto a partir do exame detalhado das transformações ocorridas na passagem das condições espaciais meta-históricas para os espaços históricos da organização humana. Pensamos, em particular, no debate corrente sobre os legados botânicos africanos para a conformação da paisagem americana (CARNEY; ROSOMOFF 2009; AHR EXCHANGE 2010) e na conceituação do capitalismo como uma ecologia-mundo, proposta por Jason Moore (2011). Pode-se dar mais consistência aos esforços inaugurados por Laurent Dubois (2004), que propôs realizar uma "história intelectual" dos sujeitos escravizados, por meio de um exame dos critérios de apreensão escrava do tempo e em que medida eles se antagonizaram à apreensão senhorial. Não se trata, aqui, de retomar a contraposição entre "tempo camponês" dos escravos e "tempo industrial" dos senhores, já bastante explorada pela historiografia, mas, antes, de analisar o peso das articulações temporais das dimensões do passado e do futuro na dinâmica do conflito social escravista, bem como suas variações no tempo e no espaço.

A agenda de pesquisa ainda aberta diz respeito não apenas ao aprofundamento das reflexões sobre a complexidade renovada da escravidão do século XIX, mas ao lançamento de novas luzes para os diferentes períodos do escravismo atlântico, desde sua estruturação no século XVI, passando pelas suas subsequentes remodelações. É preciso esclarecer as variadas formas pelas quais a escravidão negra nas Américas integrou diferentes espaços e ritmos temporais, alinhavou repetibilidades e singularidades, articulou estruturas e eventos, ajustou experiências e expectativas. Cumpre identificar analiticamente os múltiplos planos temporais em convívio, diálogo e contradição, examinando mais a fundo de que modo, em suas diferentes fases, estruturas diacrônicas de eventos e estruturas mais longevas se combinavam, permeando as múltiplas experiências dos atores históricos. Sem a pretensão de propiciar um panorama fechado, é possível dizer, por exemplo, que os estratos do tempo da escravidão americana foram compostos, em um plano preliminar, no 
âmbito metafórico de suas formações geológicas, por preceitos normativos oriundos da Antiguidade clássica, pela recorrência de um conjunto de práticas sedimentado ainda no medievo e pelo reconhecimento institucional mútuo do cativeiro que permitiria o trato dos viventes entre europeus e africanos. Essas camadas mais profundas não foram soterradas na noite dos tempos com o desenvolvimento dos sistemas atlânticos. Antes, permaneceram vivas, influindo, de maneira ressignificada a cada época, no devir da escravidão até os seus estertores. Tocar adiante esta agenda de investigação, no entanto, é tarefa para muitos historiadores e para um bom tempo de trabalho.

\section{REFERÊNCIAS BIBLIOGRÁFICAS}

AHR EXCHANGE. The Question of "Black Rice". The American Historical Review, v. 115, n. 1, p. 123-171, 2010.

ALADRÉN, Gabriel. Liberdades negras nas paragens do sul: alforria e inserção social de libertos em Porto Alegre, 1800-1835. Rio de Janeiro: Editora FGV, 2009.

. Bajo mi real protección y amparo: os decretos espanhóis de liberdade a escravos fugitivos e os conflitos imperiais no Atlântico, 1680-1791. Topoi, v. 18, n. 36, p. 514536, 2017.

ALONSO, Angela. Flores, votos e balas: o movimento abolicionista brasileiro (1868-1888). São Paulo: Companhia das Letras, 2015.

ASSIS, Arthur Alfaix; MATA, Sérgio da. Prefácio: O conceito de história e o lugar dos Geschichtliche Grundbegriffe na história da história dos conceitos. In: ENGELS, Odilo; HORST, Günther; MEIER, Christian; KOSELLECK, Reinhart. O conceito de história. Belo Horizonte: Autêntica, 2013, p. 9-34.

BAPTIST, Edward E. The half has never been told. Slavery and the making of American capitalism. New 
York: Basic Books, 2014.

BARROSO, Daniel Souza; LAURINDO Jr., Luís Carlos. À margem da Segunda Escravidão? A dinâmica da escravidão no Vale Amazônico nos quadros da economia-mundo capitalista.

Tempo, v. 23, n. 3, p. 568-588, 2017.

BECKERT, Sven. Empire of cotton. A global history. New York: Knopf, 2014.

BLACKBURN, Robin. The American crucible. Slavery, emancipation and human rights. London: Verso, 2011.

BRAUDEL, Fernand. História e Ciências Sociais: a Longa Duração. In: BRAUDEL, Fernand. Escritos sobre a história. São Paulo: Perspectiva, 1978a [1958], p. 41-77.

. Sobre uma Concepção de História Social. In: BRAUDEL, Fernand. Escritos sobre a história. São Paulo: Perspectiva, 1978b [1959], p. 161-176.

. O mediterrâneo e o mundo mediterrânico

na época de Felipe II. Volume 1. São Paulo: Edusp, 2016 [1949].

CARNEY, Judith; ROSOMOFF, Richard Nicholas. In the shadow of slavery. Africa's botanical legacy in the atlantic world. Berkeley: University of California Press, 2009.

CARDOSO, Ciro Flamarion Santana. El Modo de Producción Esclavista Colonial En América. Cuadernos de Pasado y Presente, v. 12, n. 40, p. 193-242, 1973.

CARDOSO DE MELLO, João Manuel. O capitalismo tardio. Campinas: Edições Facamp, 2009 [1978].

CHALHOUB, Sidney. Visões da liberdade. Uma história das últimas décadas da escravidão na Corte. São Paulo: Companhia das Letras, 1990. 
A força da escravidão: ilegalidade e costume no Brasil oitocentista. São Paulo: Companhia das Letras, 2012.

COSTA, Emília Viotti da. Coroas de glória, lágrimas de sangue. A rebelião dos escravos de Demerara em 1823. São Paulo: Companhia das Letras, 1998.

COUPLAND, Reginald. The british anti-slavery movement. London: Frank Cass, 1964 [1933].

DAL LAGO, Enrico. American slavery, atlantic slavery, and beyond. The U.S. "peculiar institution" in international perspective. Boulder: Paradigm Publishers, 2012.

DAIX, Pierre. Fernand Braudel. Uma biografia. Rio de Janeiro: Record, 1999.

DAVIS, David Brion. The problem of slavery in western culture. New York: Oxford University Press, 1988 [1966].

. The Problem of Slavery in the Age of Revolution, 1770-1823. Oxford: Oxford University Press, 1999 [1975].

Oxford University Press, 1984.

Slavery and Human Progress. Oxford: DOSSE, François. A História em Migalhas. Dos Annales à Nova História. São Paulo: Ensaio-Ed.Unicamp, 1992.

História do Estruturalismo. Volume 1. São

Paulo: Ensaio-Ed.Unicamp, 1993.

DUTT, Carsten. História(s) e Teoria da história: entrevista com Reinhart Koselleck. História da Historiografia, n. 18, p. 311-324, 2015.

DRESCHER, Seymour. Econocide: British Slavery in the Era of Abolition. Pittsburgh: University of Pittsburgh Press, 1977. 


\section{Abolition. A History of Slavery and}

Antislavery. Cambridge: Cambridge University Press, 2009.

DUBOIS, Laurent. Luzes escravizadas: repensando a história intelectual do Atlântico francês. Estudos Afro-asiáticos, v. 26, n. 2, p. 331-354, 2004.

ELEY, Geoff. A Crooked Line. From Cultural History to the History of Society. Ann Arbor: The University of Michigan Press, 2005.

ELTIS, David. Economic Growth and the Ending of the Transatlantic Slave Trade. New York/Oxford: Oxford University Press, 1987.

FERRARO, Marcelo R. A arquitetura da escravidão nas cidades do café. Vassouras, século XIX. Dissertação (Mestrado em Ciências). Programa de Pós-Graduação em História Social, Universidade de São Paulo, 2017.

FERRER, Ada. Freedom's Mirror. Cuba and Haiti in the age of revolution. Cambridge: Cambridge University Press, 2014.

FINLEY, Moses I. Escravidão antiga e ideologia moderna. Rio de Janeiro: Graal, 1991.

FOGEL, Robert; ENGERMAN, Stanley. Time on the cross: the economics of American negro slavery. Boston: Little, Brown and Co., 1974.

FONTANA, Josep. História: análise do passado e projeto social. Bauru: Edusc, 1998.

FRADERA, Joseph; SCHMIDT-NOWARA, Christopher (Eds.). Slavery and antislavery in Spain's Atlantic Empire. New York: Bergham Books, 2013.

FRAGOSO, João. Barões do café e sistema agrário escravista: Paraíba do Sul/Rio de Janeiro (1830-1888). Rio de Janeiro: Faperj: 7 Letras, 2013. 
FRANCASTEL, Pierre. A realidade figurativa. São Paulo: Perspectiva, 1993.

GENOVESE, Eugene. A economia política da escravidão. Rio de Janeiro: Pallas, 1976 [1965].

. Roll, Jordan, roll: the world the slaves made. New York: Pantheon Books, 1974.

GODELIER, Maurice. The mental and the material. Thought, economy and society. Londres: Verso, 1986 [1984].

GORENDER, Jacob. O escravismo colonial. São Paulo: Fundação Perseu Abramo, 2010 [1978].

GRINBERG, Keila. The two enslavements of Rufina: slavery and international relations on the southern border of nineteenthcentury Brazil. The Hispanic American Historical Review, vol. 96, n. 3, p. 259-290, 2016.

GUEDES, Roberto. Egressos do cativeiro. Trabalho, família, aliança e mobilidade social (Porto Feliz, São Paulo, c.17981850). Rio de Janeiro: Mauad X-Faperj, 2008.

GUTMAN, Herbert G. The black family in slavery and freedom, 1750-1925. New York: Pantheon Books, 1976

HEXTER, Jack. Fernand Braudel and the Monde Braudellien. The Journal of Modern History, v. 44, n. 4, p. 480-539, 1972.

HOBSBAWM, Eric. A era das revoluções, 1789-1848. Rio de Janeiro: Paz \& Terra, 1977 [1962].

IEGELSKI, Francine. A astronomia das constelações humanas. Reflexões sobre o pensamento de Claude LéviStrauss e a história. Tese (Doutorado em Ciências). Programa de Pós-Graduação em História Social, Universidade de São Paulo, 2012.

IGGERS, Georg G. The German conception of history. 
The national tradition of historical thought from herder to the present. Middletown, CN: Wesleyan University Press, 1983. Historiography in the twentieth century. From scientific objectivity to the postmodern challenge. Middletown, CN: Wesleyan University Press, 1997.

JAMES, C.L.R. Os jacobinos negros. Touissant l'ouverture e a revolução de São Domingos. São Paulo: Boitempo, 2000 [1938].

JASMIN, Marcelo. Apresentação. In: KOSELLECK, Reinhart Koselleck. Futuro passado. Contribuição à semântica dos tempos históricos. Rio de Janeiro: Contraponto; Editora PUCRJ, 2006 [1979], p. 9-12.

JOHNSON, Walter. On Agency. Journal of Social History, $v$. 37, n. 1, p. 113-124, 2003.

JORDHEIM, Helge. Against Periodization: Koselleck's Theory of Multiple Temporalities. History and Theory, n. 51, p. 151171, 2012.

KARP, Matthew. This vast southern empire. Slaveholders and the helm of American foreign policy. Cambridge, Ma.: Harvard University Press, 2016.

KOSELLECK, Reinhart. Crítica e crise. Uma contribuição à patogênese do mundo burguês. Rio de Janeiro: Contraponto; Editora - UERJ, 1999 [1957].

. The practice of conceptual history. Timing history, spacing concepts. Stanford: Stanford University Press, 2002.

Futuro passado. Contribuição à semântica dos tempos históricos. Rio de Janeiro: Contraponto; Editora PUC-RJ, 2006 [1979].

. Estratos do tempo. Estudos sobre a história. 
Rio de Janeiro: Contraponto; Editora PUC-RJ, 2014 [2000].

LARA, Silvia Hunold. Campos da violência: escravos e senhores na capitania do Rio de Janeiro, 1750-1808. São Paulo, SP: Paz e Terra, 1988.

LEFORT, Claude. Sociedade "sem história" e historicidade. In: LEFORT, Claud. As Formas da História. Ensaios de antropologia política. São Paulo: Brasiliense, 1979 [1952], p.37-56.

LÉVI-STRAUSS, Claude. Le temps du mythe. Annales. Économies, Sociétés, Civilisations, v. 26, n. 3-4, p. 533-540, 1971.

Antropología estructural. Buenos Aires:

Ed. Paidos, 1995 [1958].

MACHADO, Maria Helena P.T. O Plano e o pânico. Os movimentos sociais na década da abolição. São Paulo: EduspEd.UFRJ, 1994.

MAMIGONIAN, Beatriz G. Africanos livres. A abolição do tráfico de escravos no Brasil. São Paulo: Companhia das Letras, 2017.

MARQUES, Leonardo. The United States and the transatlantic slave trade to the Americas, 1776-1867. New Haven: Yale University Press, 2016.

MARQUESE, Rafael de Bivar. Capitalismo, escravidão e a economia cafeeira do Brasil no longo século XIX. Saeculum (UFPB), v. 29, p. 289-321, 2013.

MARQUESE, Rafael de Bivar; SALLES, Ricardo. (org.) Escravidão e capitalismo histórico no século XIX. Cuba, Brasil e Estados Unidos. Rio de Janeiro: Civilização Brasileira, 2016.

MARQUESE, Rafael de Bivar; PARRON, Tâmis; BERBEL, 
Márcia. Slavery and Politics. Brazil and Cuba, 17901850. Albuquerque: University of New Mexico Press, 2016.

MELLO, Pedro Carvalho de; SLENES, Robert W. Análise econômica da escravidão no Brasil. In: NEUHAUS, Paulo (Org.). Economia brasileira: uma visão histórica. Rio de Janeiro: Campus, 1980, p. 89-122.

MOORE, Jason W. Ecology, Capital, and the Nature of Our Times: Accumulation and Crisis in the Capitalist WorldEcology. Journal of World-Systems Research, v. 17, n. 1, p. 108-147, 2011.

MORENO, Breno A. S. Demografia e trabalho escravo nas propriedades rurais cafeeiras de Bananal, 18301860. Dissertação (Mestrado em Ciências). Programa de Pós-Graduação em História Social, Universidade de São Paulo, 2013.

MORENO FRAGINALS, Manuel. O Engenho: complexo socioeconômico açucareiro cubano. São Paulo: HucitecUnesp, 2 volumes, 1987 [1976].

MORERA, Esteve. Gramsci's historicism. A realist interpretation. London: Routledge, 1990.

MUAZE, Mariana; SALLES, Ricardo (Orgs.). O Vale do Paraíba e o Império do Brasil nos quadros da Segunda Escravidão. Rio de Janeiro: 7 Letras-Faperj, 2015.

NOVAIS, Fernando A. Portugal e Brasil na crise do Antigo Sistema Colonial (1777-1808). São Paulo: Hucitec, 1979.

OLSEN, Niklas. History in the plural. An introduction to the work of Reinhart Koselleck. New York: Berghahn Books, 2012.

PALTI, Elias José. Introducción. In: KOSELLECK, Reinhart. Los estratos del tiempo: estudios sobre la historia. Barcelona: Paidós, 2001, p. 9-33. 
PARRON, Tâmis Peixoto. A política da escravidão na era da liberdade: Estados Unidos, Brasil e Cuba, 1787-1846. Tese (Doutorado em Ciências). Programa de Pós-Graduação em História Social, Universidade de São Paulo, São Paulo, 2015.

PIQUERAS, José Antonio. La esclavitud en las Españas: un Lazo Transatlántico. Madrid: Catarata, 2011.

. The Return to the Casa de Vivienda and the Barracón: The Terms of Social Action in Slave Plantations. In: TOMICH, Dale (Ed.). The politics of the Second Slavery. Albany: State University of New York Press, p. 83-111, 2016.

REIS, José Carlos. A temporalidade e seus críticos. In: LOPES, Marcos Antônio (org.). Fernand Braudel. Tempo \& história. Rio de Janeiro: Edtora FGV, 2003, p. 111-122.

Tempo \& História. Tempo Histórico, História do Pensamento Ocidental e Pensamento Brasileiro. Rio de Janeiro: Editora FGV, 2012.

ROBERTS, Justin. Slavery and the enlightenment in the British Atlantic, 1750-1807. Cambridge: Cambridge University Press, 2013.

ROOD, Daniel B. The reinvention of atlantic slavery: technology, labor, race, and capitalism in the Greater Caribbean. Oxford: Oxford University Press, 2017.

SALLES, Ricardo. E o Vale era o escravo - Vassouras, século XIX. Senhores e escravos no coração do Império. Rio de Janeiro: Civilização Brasileira, 2008.

SANTOS, Marco Aurélio dos. Geografia da escravidão no Vale do Paraíba cafeeiro. Bananal, 1850-1888. São Paulo: Alameda, 2016.

SANTOS, Ynaê Lopes dos. Irmãs do Atlântico. Escravidão e espaço urbano no Rio de Janeiro e Havana (1763-1844). Tese 
(Doutorado em Ciências). Programa de Pós-Graduação em História Social, Universidade de São Paulo, São Paulo, 2012.

SARTRE, Jean-Paul. O existencialismo é um humanismo / A Imaginação / Questão de Método. São Paulo: Abril Cultural, 1978 [1957].

SCHMIDT-NOWARA, Christopher. Slavery, freedom, and abolition in Latin America and the Atlantic World. Albuquerque: University of New Mexico Press, 2011.

SILVA JR., Waldomiro Lourenço da. História, direito e escravidão. A legislação escravista no antigo regime iberoamericano. São Paulo: Annablume, 2013.

Entre a escrita e a prática: direito e escravidão no Brasil e em Cuba, c.1760-1871. Tese (Doutorado em Ciências). Programa de Pós-Graduação em História Social, Universidade de São Paulo, São Paulo, 2015.

SMITH, Mark M. Mastered by the clock. Time, slavery, and freedom in the American South. Chapel Hill: The University of North Carolina Press, 1997.

SOUZA, Priscila de Lima. Sem que lhes obste a diferença de cor. A habilitação dos pardos livres no Brasil e no Caribe espanhol (1750-1808). Tese (Doutorado em Ciências). Programa de Pós-Graduação em História Social, Universidade de São Paulo, 2017.

STEPHEN, James. The slavery of the British West India colonies delineated: as it exists both in law and practice, and compared with the slavery of other countries, ancient and modern. London: J. Butterworth and Son, 1830.

TOMICH, Dale. Pelo prisma da escravidão. Trabalho, capital e a economia mundial. São Paulo: Edusp, 2011 [2004].

A escravidão no capitalismo histórico: rumo a uma história teórica. In: MARQUESE, Rafael de Bivar; 
SALLES, Ricardo Salles (Org.). Escravidão e capitalismo histórico no século XIX. Cuba, Brasil e Estados Unidos. Rio de Janeiro: Civilização Brasileira, 2016, p. 55-97, 2016

WALLON, Henri Alexandre. Histoire de l'esclavage dans I'antiquité. Paris: Imp. Royale, 1847.

WILLIAMS, Eric. Capitalismo e escravidão. São Paulo: Companhia das Letras, 2012 [1944].

YOUSSEF, Alain El. Imprensa e escravidão. Política e tráfico negreiro no império do Brasil (Rio de Janeiro, 1822-1850). São Paulo: Intermeios, 2016.

\section{AGRADECIMENTOS E INFORMAÇŌES}

Rafael de Bivar Marquese

marquese@usp.br

Doutor em História Econômica (Universidade de São Paulo)

Professor do Departamento de História da FFLCH/USP

Livre-docente em História da América Colonial

Waldomiro Lourenço da Silva Júnior

waldomiro.silva@ufsc.br

Doutor em História Social (Universidade de São Paulo)

Professor adjunto da Universidade Federal de Santa Catarina

Além de agradecer aos pareceristas da revista História da Historiografia, gostaríamos de agradecer os valiosos comentários de amigos e colegas que colaboraram na execução deste artigo: Alain El Youssef, Aline Silveira, Beatriz Mamigonian, Dale Tomich, Fabio Morales, João Paulo Pimenta, Leonardo Marques, Miguel Palmeira, Ricardo Salles, Rodrigo Bonaldo, Tâmis Parron, Tiago Kramer. Agradecemos, também, aos pesquisadores do LabMundi/USP e à Linha de Pesquisa História Global do Trabalho/ UFSC, que o discutiram em seminários internos. Rafael Marquese agradece, ainda, ao CNPq, a cuja bolsa de produtividade se vincula o presente artigo. 